\title{
贡嘎山东坡中更新世晚期以来冰川作用 年代学研究
}

\author{
王杰，潘保田，张国梁，崔航，曹泊，耿豪鹏 \\ 兰州大学西部环境教育部重点实验室, 兰州 730000 \\ *E-mail: wangjie@1zu.edu.cn
}

收稿日期: 2012-02-21; 接受日期: 2012-07-15

国家自然科学基金(批准号: 41171063)、中央高校基本科研业务费专项资金(编号: LZUJBKY-2010-114)、中国科学院寒区早区环境与工程 研究所冰冻圈科学国家重点实验室开放基金(编号: SKLCS 2011-03)和科技部科技基础性工作专项项目(编号: 2006FY110200)资助

\begin{abstract}
摘要＼cjkstart青藏高原东缘最高山地一贡嘎山是横断山最大的现代冰川作用中心, 第四纪冰期中冰 川有较大规模的扩张, 留下了形态较完整的冰川和冰水沉积地形. 根据冰碛物的分布与风化程 度、冰碛地层的接触关系以及表面土壤发育状况等，应用 ESR 和 OSL 测年技术，对该地区的第 四纪冰川沉积进行了定年, 其年龄分别为 $(2.2 \pm 0.5),(11.9 \pm 0.6),(35.9 \pm 2.7) \sim(58.0 \pm 6.3)$ 与 (119.2 \pm 15.9$) ~(194.2 \pm 32.8) \mathrm{ka}$. 应用地貌地层学原理并结合已有的研究资料, 确认贡嘎山东坡至 少经历了 5 次规模较大的冰进，可分别对应于小冰期、新冰期、MIS2, MIS3 中期和 MIS6. 本区 的末次冰期冰川规模最大不是发生在末次冰期最盛期，而是气候较为冷湿的 MIS3 中期. 早期划 定的贡嘎、南门关和雅家埂冰期分别对应于末次冰期晚冰阶、中冰阶和倒数第二次冰期 (MIS6). 磨西台地中上部、两侧阶地及尾部均为 MIS3 至全新世的混杂有泥石流堆积的冰水沉积; 而底部 主要是南门关冰期(MIS3 中期)的冰川沉积, 其中包含有冰水砂砾石层透镜体和冰湖相等沉积.
\end{abstract}

关键词 贡嘎山 冰川地貌 ESR 测年 OSL 测年 磨西台地
青藏高原及其周边山地因受剧烈构造抬升的影 响，河流下切可致较老的冰川地形被保存在台地、分 水岭或谷肩等相对较高的位置, 为相对完整的第四 纪冰川演化序列的建立提供了最重要的载体. 同时, 高原及周边山地第四纪冰川是构造隆升和全球冰期 气候耦合的产物, 不同地区的大气环流模式、抬升时 间、速率及隆升幅度等存在一定差异, 造成各地各次 冰期规模不同, 甚至同一冰期各地冰川规模及演化 趋势也不同 ${ }^{[1,2]}$. 近年来, 随着可对冰川地形(冰川侵 蚀与沉积地形)进行直接定年的测年技术的发展与应 用, 中外学者应用一种或数种方法对上述一些地区
的冰川地形进行了定年研究 ${ }^{[3 \sim 11]}$, 这为冰川时空演化 的对比研究提供了可能, 也为冰川地貌演化模拟与 古环境重建提供了基本资料, 在构造活跃的地区还 可为山地的构造抬升提供理论参考.

贡嘎山地处青藏高原东部边缘, 位于四川盆地 向青藏高原过渡的大雪山中段, 第四纪以来, 新构造 运动活跃, 差异性断块抬升十分强烈. 区内近南北走 向的高大雄伟山体是冰川发育的依托, 形成了横断 山最大的现代冰川作用中心, 第四纪期间多次冰川 作用留下了丰富的古冰川遗迹, 冰川堆积和侵蚀地 形可以互相匹配, 特别是沉积地形保存更为清晰. 已

英文引用格式: Wang J, Pan B T, Zhang G L, et al. Late Quaternary glacial chronology on the eastern slope of Gongga Mountain, eastern Tibetan Plateau, China. Science China: Earth Sciences, 2012, doi: 10.1007/s11430-012-4514-0 
有多位中外学者对贡嘎山的冰川地貌进行了研 究 ${ }^{[12 ~ 23]}$, 但对冰川作用期次的划分尚存在分歧. 虽 然早期研究中获得了部分冰碛物中朽木的 ${ }^{14} \mathrm{C}$ 定年数 据 ${ }^{[18,19,21]}$, 最近 Owen 等 ${ }^{[11]}$ 利用宇宙成因核素 (terrestrial cosmogenic nuclide, $\mathrm{TCN}$ ) ${ }^{10} \mathrm{Be}$ 技术也测定 了海螺沟内冰碛和磨西台地的暴露时代, 但都是针 对末次冰期晚冰阶(marine isotope stage (MIS)2)以来 的冰川和冰水堆积, 更老的冰碛仍然缺少绝对定年 资料. 本文在详尽野外考察的基础上, 应用电子自旋 共振(electron spin resonance, ESR)和光释光(optically simulated luminescence, OSL)测年技术对贡嘎山东坡 冰川和冰水沉积进行定年, 为贡嘎山地区第四纪冰 川演化提供新的年代学证据. 应用地貌地层学原理 并结合已有的其他气候记录进一步探讨受季风环流 控制的贡嘎山地区的冰川演化模式.

\section{1 研究区概况}

贡嘎山 $\left(29^{\circ} 20^{\prime} \sim 30^{\circ} 20^{\prime} \mathrm{N}, 101^{\circ} 30^{\prime} \sim 102^{\circ} 15^{\prime} \mathrm{E}\right)$ 最高 峰 $7556 \mathrm{~m}$, 主峰附近海拔超过 $6000 \mathrm{~m}$ 的山峰有 28 座, 海拔 $5000 \mathrm{~m}$ 以上山体面积占全区总面积的 $1 / 6^{[24]}$ (图 1). 山高谷深、地势高差悬殊是本区地貌上 的显著特征, 如东坡, 从大渡河谷至山顶水平距离 $29 \mathrm{~km}$, 而相对高差达 $6500 \mathrm{~m}$ 之多. 该区域主要受东 南和西南季风及高空西风环流的控制, 气候上介于 亚热带暖湿季风气候向青藏高原高寒气候区的过渡 带上 ${ }^{[20]}$. 据东坡海螺沟气象站 $\left(29.573^{\circ} \mathrm{N}, 101.992^{\circ} \mathrm{E}\right.$, $3000 \mathrm{~m}$ ) 的观测资料, $1988 \sim 2005$ 年平均气温为 $4.1^{\circ} \mathrm{C}$, 年平均降水量为 $1619 \mathrm{~mm}$, 降水主要集中在 5 8 月, 占全年降水的 $80 \%$ 以上.

贡嘎山地区围绕主峰发育有 74 条, 总面积为 $257.66 \mathrm{~km}^{2}$ 的典型季风海洋型冰川 ${ }^{[25]}$, 长度超过 10 $\mathrm{km}$ 的山谷冰川有 5 条(表 1), 分别是东坡的海螺沟、 磨子沟、燕子沟、南门关沟和西坡的大贡巴冰川 (图 1). 东坡的现代冰川平衡线高度(equilibrium line altitudes, ELAs)在 4800 5000 m, ELAs 处的年平均气 温 $-4.4^{\circ} \mathrm{C}$, 年平均降水量 $3000 \mathrm{~mm}$; 而西坡的 ELAs 在 $5000 \sim 5200 \mathrm{~m}$ 左右, ELAs 处的年平均气温 $-4.1 \sim-5^{\circ} \mathrm{C}$, 年平均降水量 $1800 \mathrm{~mm}^{[26]}$.

\section{2 贡嘎山东坡的第四纪冰川与冰水沉积}

\section{1 冰川沉积}

贡嘎山东坡分布有 33 条, 总面积为 $155.10 \mathrm{~km}^{2}$ 的现代冰川 ${ }^{[25]}$. 冰川的总面积与规模都要大于西坡, 长度 $>10 \mathrm{~km}$ 的就有 4 条. 因此东坡的冰川遗迹分布 比较广泛, 其中形态较为清晰的冰碛有 5 套(图 2).

贡嘎山东坡现代冰川外围一般都有数列新鲜的 冰碛垄, 分布在距冰川末端数百米至 $3 \mathrm{~km}$ 范围内 ${ }^{[20]}$. 如海螺沟冰川末端至大岩窝附近, 就分布有 3 列形态 清晰终碛垄(图 3). 最内侧终碛垄分布在海拔 $2850 \mathrm{~m}$ 处, 高出谷底约 $30 \mathrm{~m}$; 从尾端其向下约 $0.75 \sim 1 \mathrm{~km}$, 为最外侧的终碛垄 $(2800 \mathrm{~m})$, 该垄高出谷底 50 100 $\mathrm{m}$; 中间一列终碛垄多与最外侧终碛垄相重叠, 形态 上较难区分.

第二套一般分布在第一套冰碛的外侧及向下不 远的谷地, 形态较为高大. 在海螺沟中保存较为完好 (图 3), 从海拔 $2750 \mathrm{~m}$ 向上至海拔 $3300 \mathrm{~m}$ 观景台附 近，断续分布着 3 列冰碛垄，以中间一列的规模最大， 被称为大岩窝冰进 ${ }^{[18]}$ 或观景台冰进 ${ }^{[21]}$, 而最内与最 外一列分别被称为海螺沟冰进 ${ }^{[18]}$ 和前观景台冰进 ${ }^{[21]}$. 燕子沟冰川两侧也分布有比冰面高出 80 160 m 高大 侧碛垄，向下一直延伸到 $3580 \mathrm{~m}$ 处.

海螺沟中第三套冰碛是分布在海拔 1850 3000 $\mathrm{m}$ 冰川槽谷北侧的冰碛台地. 该套冰碛所代表的冰 川作用被称为海螺沟冰期 ${ }^{[16,17]}$ 或贡嘎冰期 ${ }^{[27]}$. 热水 沟口一带冰碛剖面分为不整合接触的三层，上、下两 层为灰白色的冰碛; 中层为厚约 $4 \mathrm{~m}$ 的河湖相砂质淤 泥层. 该套冰碛在燕子沟中, 主要分布在药王庙以西

表 1 贡嘎山地区长度 $>10 \mathbf{~ k m}$ 山谷冰川及相关参数 ${ }^{[25]}$

\begin{tabular}{cccccccc}
\hline 冰川名称和编号 & $\begin{array}{c}\text { 长度 } \\
(\mathrm{km})\end{array}$ & $\begin{array}{c}\text { 平均宽度 } \\
(\mathrm{km})\end{array}$ & $\begin{array}{c}\text { 消融区朝向 } \\
\text { 海螺沟 }(5 \mathrm{~K} 612 \mathrm{~F}-3)\end{array} \quad \begin{array}{c}\text { 面积 } \\
\left(\mathrm{km}^{2}\right)\end{array}$ & $\begin{array}{c}\text { 冰储量 } \\
\left(\mathrm{km}^{3}\right)\end{array}$ & $\begin{array}{c}\text { 最高海拔 } \\
(\mathrm{m})\end{array}$ & $\begin{array}{c}\text { 末端高度 } \\
(\mathrm{m})\end{array}$ & $\begin{array}{c}\text { 雪线高度 } \\
(\mathrm{m})\end{array}$ \\
磨子沟 $(5 \mathrm{~K} 612 \mathrm{~F}-8)$ & 11.1 & 2.0 & $\mathrm{SE}$ & 25.71 & 3.3423 & 7556 & 2980 \\
燕子沟(5K612F-13) & 10.5 & 3.1 & $\mathrm{NE}$ & 26.76 & 3.5056 & 6886 & 3600 \\
南门关沟(5K612F-25) & 10.0 & 1.7 & $\mathrm{NE}$ & 32.15 & 4.4689 & 7556 & 3680 \\
大贡巴(5K612D-44) & 11.0 & 1.8 & $\mathrm{E}$ & 16.71 & 1.8882 & 6540 & 3460 \\
\hline
\end{tabular}

1890 


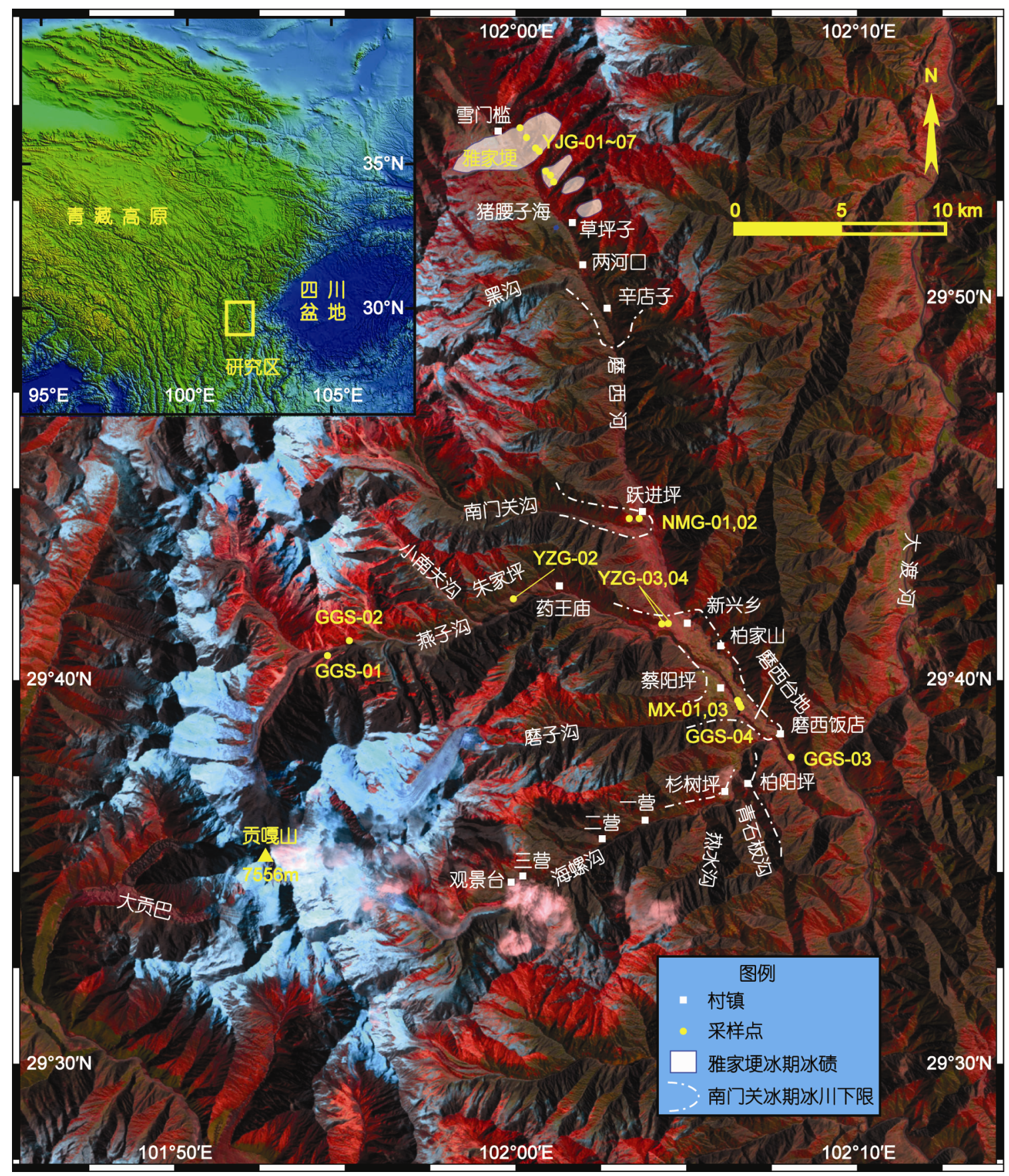

图 1 贡嘎山地区 TM(Thematic Mapper)遥感影像及采样置图

谷地北岸的朱家坪附近, 另外从遥感影像上可以看 到现代磨子沟冰川末端的东北面有一长约 $4 \mathrm{~km}$ 的 $\mathrm{U}$ 形谷(图 1), 可以判断当时磨子沟冰川有一部分冰流 是流向燕子沟的. 磨西河上源, 来自雪门槛两侧的古 冰川抵达两河口北海拔 $3100 \mathrm{~m}$ 处, 形成猪腰子海冰 碛湖; 而西侧支沟黑沟的古冰川形成的高侧碛沿磨
西河分布至 $2950 \mathrm{~m}$ 的辛店子附近 ${ }^{[22]}$.

第四套多以冰碛台地、终碛垄和冰碛丘陵等形式 分布在槽谷口和山麓地带(图 2). 在海螺沟中, 该套 冰碛主要分布于杉树坪之西至斑竹园一带, 当时青 石板沟的古冰川与海螺沟主谷冰川相汇合，冰舌下 伸至海螺沟沟口附近, 但未进入磨西宽谷 ${ }^{[22]}$. 南门关 


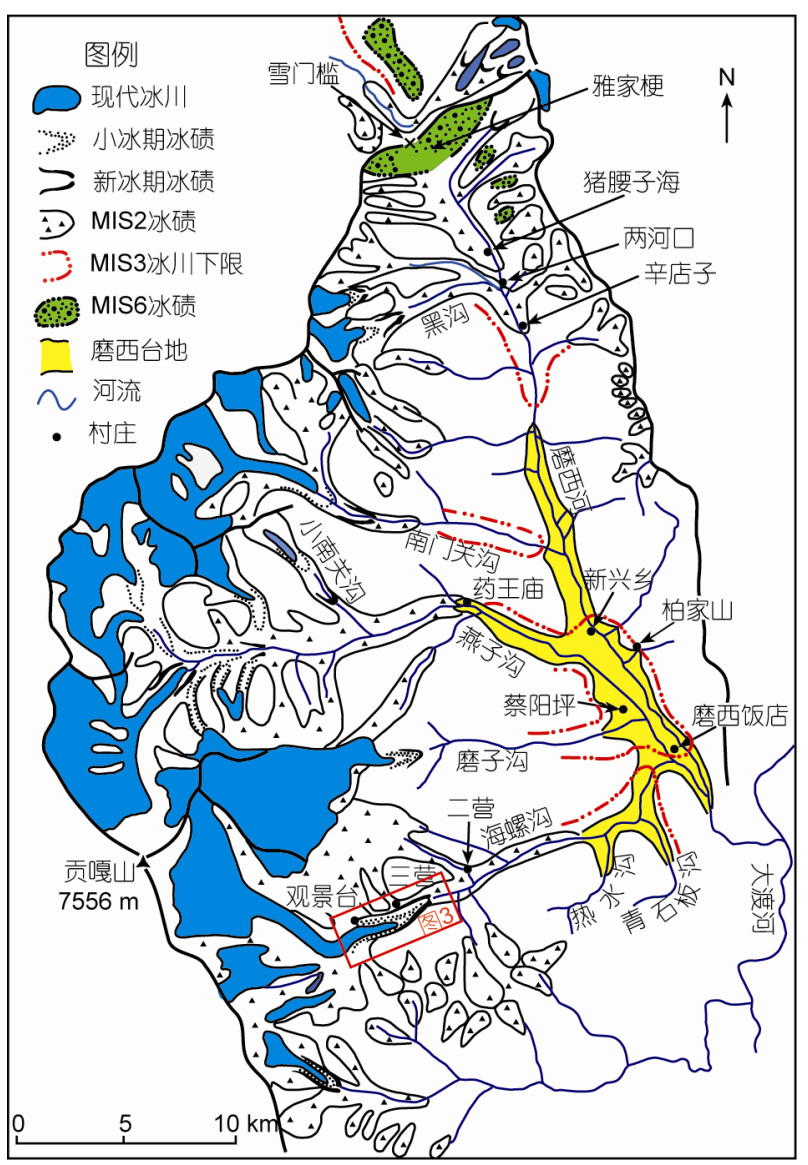

图 2 贡嘎山东坡第四纪冰川遗迹分布图 据文献[22]修改
沟中以冰碛平台形式分布于沟口北侧的跃进坪, 表 面的大漂砾直径达 $2 \mathrm{~m}$ 以上, 冰碛台地上部发育有红 褐色土层. 王明龙等 ${ }^{[19]}$ 将该套冰碛代表的冰期命名 为南门关冰期. 燕子沟中该期冰碛自药王庙向下的 谷地两侧均有出露, 出沟口北侧山坡旁的冰碛大小 混杂, 呈半胶结状态. 当时燕子沟冰川进入磨西河谷 后汇合磨子沟冰川, 估计冰舌下伸至海拔 $1550 \mathrm{~m}$ 左 右 ${ }^{[22]}$.

第五套冰碛一般分布在谷地源头以及谷地较高 位置, 由于风化侵蚀, 保留较少. 磨西河上游雅家埂 东侧海拔 3700 3800 m 间, 有一高冰碛台地, 呈丘陵 状, 冰碛厚约 $100 \mathrm{~m}$, 高出河床 $300 \mathrm{~m}$ 左右. 冰碛风 化很强, 砾石表面有厚 3 5 mm 棕色风化壳, $20 \mathrm{~cm}$ 粒 径的砾石用锤轻击便碎. 因此, 该套冰碛代表的冰期 被命名为雅家埂冰期 ${ }^{[15,19]}$ ，从其的保持位置判断当 时的冰川为山麓冰川.

\section{2 冰水沉积}

来自燕子沟、磨子沟和海螺沟的冰川、冰水和洪 积泥石流沉积, 在新兴乡与磨西镇之间形成长约 10 $\mathrm{km}$, 宽 1 2 km, 由砂砾石组成, 厚达 $120 \mathrm{~m}$ 左右的磨 西台地, 又称磨西面 ${ }^{[21]}$ (图 2,4). 东坡外围谷地中则 广泛发育了多级冰水阶地、扇形地. 根据我们的野外 考察和文献资料分析，磨西面及附近的各级阶地与

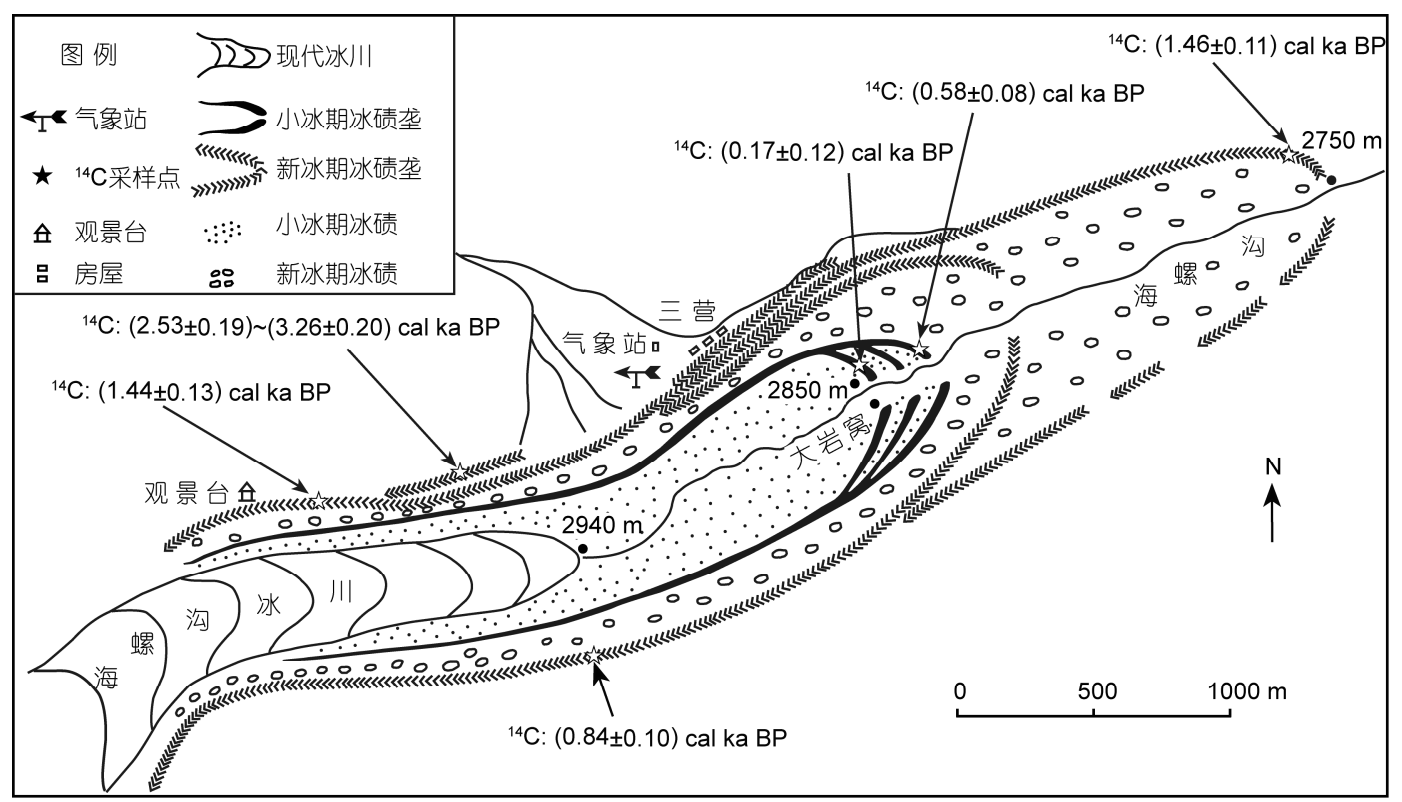

图 3 海螺沟新冰期以来的冰碛分布

据文献[21]修改 
南门关冰期后的冰川融水和冰川进退关系十分密切. 该区域河流短促, 河床比降大, 大多源于新老冰 碛物覆盖区, 因此冲积物中砾石的磨圆度和分选一 般均较差. 磨西台地以东, 由于磨西河的堆积和侵蚀 下切形成 4 级阶地, 在新兴乡东侧分别高出河床 $5 \sim 10,35,65$ 和 $85 \mathrm{~m}$, 最高一级 $\left(\mathrm{T}_{4}\right)$ 阶地沉积物可分 为 13 层, 包括砾石层、含砾石层、淤泥层等, 其下部 第一层和中部第七层的最大砾石直径达 $40 \mathrm{~cm}^{[21]}$. 燕 子沟多级河流阶地主要保存在药王庙和磨西河右岸 的蔡阳坪附近, 药王庙附近发育的 4 级阶地分别高出 河床 5 10, 30, 50 和 $100 \mathrm{~m}$. 海螺沟中亦发育有 4 级河 流阶, 在海螺沟沟口拔河高度分别为 5 10, 30, 90 和 $140 \mathrm{~m}$, 直到一营与二营之间仍可见到分布于第三套
冰碛旁的 $\mathrm{T}_{1}(5 \sim 10 \mathrm{~m})$ 和 $\mathrm{T}_{2}(20 \sim 25 \mathrm{~m})$ 两级阶地.

\section{3 研究方法}

本研究的测年样品采自贡嘎山东坡天然或人工 开挖的剖面中(图 1), 应用 OSL 与 ESR 测年方法对其 进行测定. 此外, 结合该区域冰川和冰水沉积已获得 的 ${ }^{14} \mathrm{C}$ 年代数据, 并将它们用 CALIB Rev. 6.1.0 程序 的 IntCal09 数据库校正成日历年龄 ${ }^{[28]}$ (表 2).

\subsection{OSL 测年}

样品的预处理和测试在兰州大学西部环境教育 部重点实验室 OSL 年代实验室中完成, 预处理方法
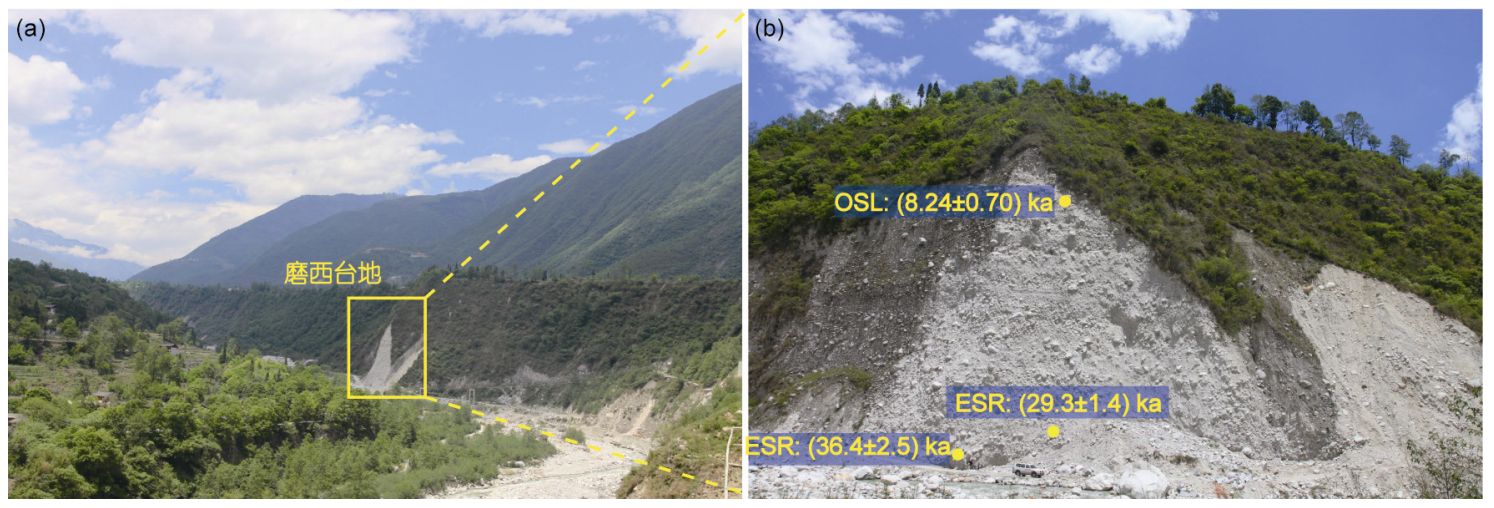

图 4 磨西台地及蔡阳坪对面的剖面

表 2 贡嘎山东坡冰川与冰水沉积 ${ }^{14} \mathrm{C}$ 数据

\begin{tabular}{|c|c|c|c|c|}
\hline 样品位置 & 测年材料 & $\begin{array}{l}{ }^{14} \mathrm{C} \text { 年龄 } \\
(\mathrm{a} B P \text { ) }\end{array}$ & 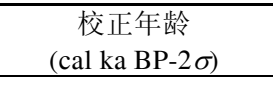 & 文献 \\
\hline 海螺沟第一套最外一列终碛 & 朽木 & $540 \pm 70$ & $0.58 \pm 0.08$ & [21] \\
\hline 海螺沟第一套最里一列侧碛 & 朽木 & $150 \pm 60$ & $0.17 \pm 0.12$ & [21] \\
\hline 海螺沟第二套内侧碛 & 朽木 & $940 \pm 50$ & $0.84 \pm 0.10$ & [18] \\
\hline 海螺沟第二套中间侧碛 & 朽木 & $1550 \pm 70$ & $1.44 \pm 0.13$ & [21] \\
\hline 海螺沟第二套中间侧碛 & 朽木 & $1580 \pm 60$ & $1.46 \pm 0.11$ & [18] \\
\hline 海螺沟第二套外侧碛 & 朽木 & $2430 \pm 80 \sim 3080 \pm 80$ & $2.53 \pm 0.19 \sim 3.26 \pm 0.20$ & [21] \\
\hline 小南关沟距现代冰川 $2 \mathrm{~km}$ 冰碛 & 朽木 & $780 \pm 90$ & $0.77 \pm 0.14$ & [21] \\
\hline 海螺沟第三套冰碛热水沟剖面中层 & 淤泥层 & $24390 \pm 750$ & $29.25 \pm 1.51$ & [19] \\
\hline 海螺沟第三套冰碛热水沟剖面上层 & 泉华盖层 & $17900 \pm 300$ & $21.31 \pm 0.85$ & [18] \\
\hline 新兴乡东 $\mathrm{T}_{4}$ 阶地底部 & 淤泥层 & $7240 \pm 90 \sim 7430 \pm 300$ & $8.22 \pm 0.29 \sim 8.25 \pm 0.57$ & [17] \\
\hline 磨西柏家山附近 $\mathrm{T}_{2}$ 底部 & 朽木 & $2350 \pm 95$ & $2.46 \pm 0.17$ & [17] \\
\hline 燕子沟药王庙上游 $1 \mathrm{~km}$ 处 $\mathrm{T}_{2}$ 中上部 & 朽木 & $1490 \pm 70$ & $1.41 \pm 0.12$ & [17] \\
\hline 小南关沟口附近 $\mathrm{T}_{1}$ & 朽木 & $732 \pm 30$ & $0.69 \pm 0.04$ & [16] \\
\hline 海螺沟观景台 $\mathrm{T}_{1}$ 砾石层 & 朽木 & $930 \pm 30$ & $0.85 \pm 0.07$ & [21] \\
\hline 海螺沟观景台 $\mathrm{T}_{2}$ & 淤泥 & $1200 \pm 70 \sim 2170 \pm 60$ & $1.13 \pm 0.15 \sim 2.18 \pm 0.15$ & [21] \\
\hline 西藏若果冰进 & 朽木 & $1540 \pm 85 \sim 1920 \pm 110$ & $1.45 \pm 0.16 \sim 1.87 \pm 0.27$ & [29] \\
\hline
\end{tabular}


及步骤见文献[30]. 选取 90 125 $\mu \mathrm{m}$ 的颗粒后, 使用 $\mathrm{H}_{2} \mathrm{O}_{2}$ 去除有机质, 稀 $\mathrm{HCl}$ 去除碳酸岩, 十二胺浮选, $\mathrm{HF}$ 溶解长石并蚀去石英颗粒的表层. 在丹麦生产的 Ris $\varphi$ DA-15 OSL/TL reader 上采用单片再生剂量法 (single-aliquot regenerative-dose, SAR $)^{[31]}$, 测定等效 剂量(equivalent dose, $D e$ )(图 5). 采用中子活化技术 测量了样品的 $\mathrm{U}, \mathrm{Th}$ 和 $\mathrm{K}$ 含量, 样品的含水量采用实 测值, 计算年剂量率时也考虑了宇宙射线的贡献 ${ }^{[32]}$. 测年结果与相关参数见表 3 .

OSL 测年的一个重要前提是样品在被埋藏前经 历了充分地曝光, 释光信号是样品埋藏之后接受辐 射重新累积获得. 研究表明, 冰川沉积存在其信号不 完全晒退的问题 ${ }^{[33 \sim 35]}$, 但山地冰川受下伏地形的影 响, 从积累区到末端, 经过多次的伸张流和压缩流交 替, 通过冰内的剪切面, 进入冰川的岩屑有较大的曝 光机会, 因此青藏高原及周边山地的冰川沉积存在 完全曝光的可能 ${ }^{[36]}$. 另外, 从冰川沉积的曝光程度与 曝光可能性推断, 表碛>内碛>底碛, 冰水沉积>冰碛 (冰川直接沉积)等 ${ }^{[33]}$. 故适当的样品采集策略与测定 方案有助于解决冰碛物可能存在的曝光不完全的缺 陷, 最终获得较为可信的测年结果 ${ }^{[33 \sim 35]}$. 该次测定 的 4 个样品中, GGS-02 直接采自冰碛物, 其年龄与冰 川的沉积序列完全不符, 明显偏老外, 其余 3 个样品 为透镜体, 结果与地貌沉积关系及已有 ${ }^{14} \mathrm{C}$ 与 $\mathrm{TCN}$ ${ }^{10} \mathrm{Be}$ 测年结果均有很好的一致性.

\subsection{ESR 测年}

ESR 采集时多选取冰碛中的沙质透镜体, 避免 阳光的直接照射, 装入黑色塑料袋中闭光运送到实
验室, 在运输过程中避免剧烈碰撞摩擦或受热. 样品 预处理是在兰州大学西部环境教育部重点实验室年 代学实验室中进行, 在室内自然光下观测不到 $\mathrm{Ge}$ 心 信号的减少现象 ${ }^{[37,38]}$, 因此该次测试样品的预处理 是在室内自然光下进行的, 样品的预处理处理方法 与步骤见文献 $[39,40]$. 处理好的样品用 ${ }^{60} \mathrm{Co}$ 进行了 人工辐照, 辐照剂量率为 $28.51 \mathrm{~Gy} \mathrm{~min}^{-1}$, 辐照后的 样品由中国地震局地质所新构造年代学实验室进行 测定, 测试仪器为德国 Bruker 公司生产的 EMX1/ 6ESR 谱仪, 选用石英颗粒中的 $\mathrm{Ge}$ 心作为测年信号, 测试条件及参数: 室温、 $\mathrm{X}$ 波段、微波功率 $=2.021$ $\mathrm{mW}$ 、中心磁场 $=3525 \mathrm{G}$ 、扫描宽度 $50 \mathrm{G}$ 、仪器频 率 $=9.852 \mathrm{GHz}$ 、调制频率 $=100 \mathrm{kHz}$ 、调制振幅 $=1 \mathrm{G}$ 、 时间常数 $=40.96 \mathrm{~ms}$ 、扫描时间 $=10.486 \mathrm{~s}$. 根据人工辐 照剂量与其对应的 ESR 信号强度, 用最小二乘法对 所测得的数据进行线性拟合并用外推法将拟合的直 线外推到信号强度为零的横坐标得出 $D_{e}$ (图 6). 样品 所在环境中 $U$ 和 $\mathrm{Th}$ 元素的浓度与 $\mathrm{K}_{2} \mathrm{O}$ 的百分比, 由 中国原子能科学研究院用中子活化技术进行测定. 年剂量率由测定样品的 $\mathrm{U}$ 和 $\mathrm{Th}$ 的浓度、 $\mathrm{K}_{2} \mathrm{O}$ 的含量、 样品的含水量、以及宇宙射线的贡献率 ${ }^{[22]}$ 来换算. 测 年结果与相关参数见表 3.

研究表明石英颗粒中的 $\mathrm{Ge}$ 对光照与研磨比较敏 感，这两种机制都可使它的信号归零 ${ }^{[41 ~ 43]}$. 首先根 据山岳冰川的运动理论, 冰川携带的物质在冰川运 动过程中有曝光的机会 ${ }^{[44]}$, 这个过程也对其携带的 物质也进行了研磨, 如冰川沉积中细颗粒物质基本 上都是这种方式形成的 ${ }^{[45,46]}$; 其次是 $\mathrm{Ge}$ 心的光吸收 带为 $4.43 \mathrm{eV}^{[47]}$, 大致相当于波长为 $280 \mathrm{~nm}$ 的紫外光,
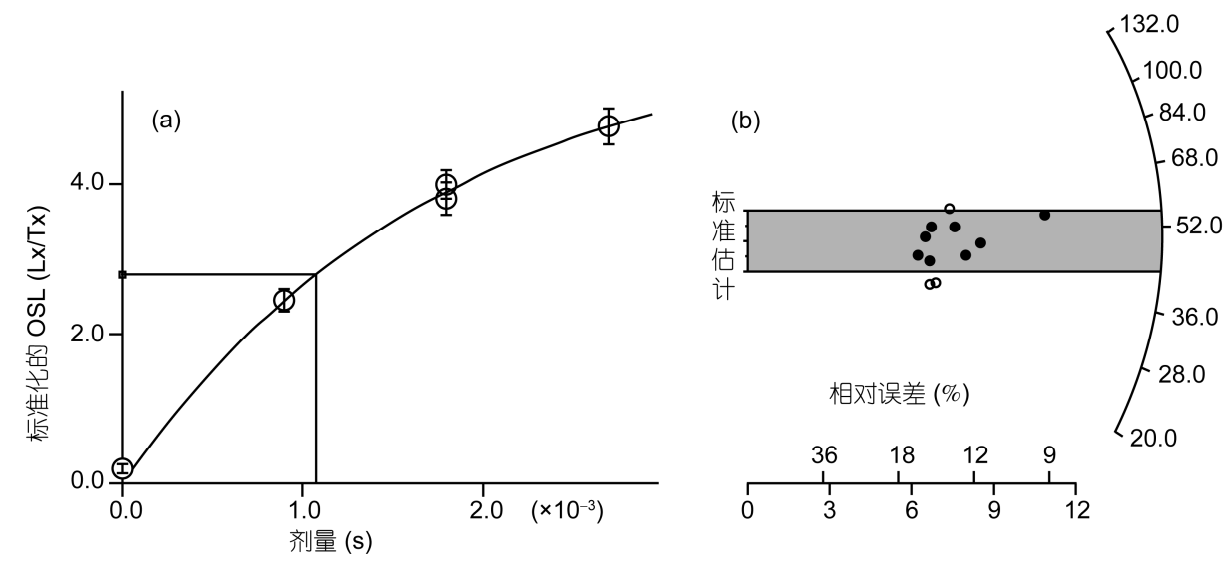

图 5 样品 GGS-04 的生长曲线(a)与等效剂量分布放射图(b) 


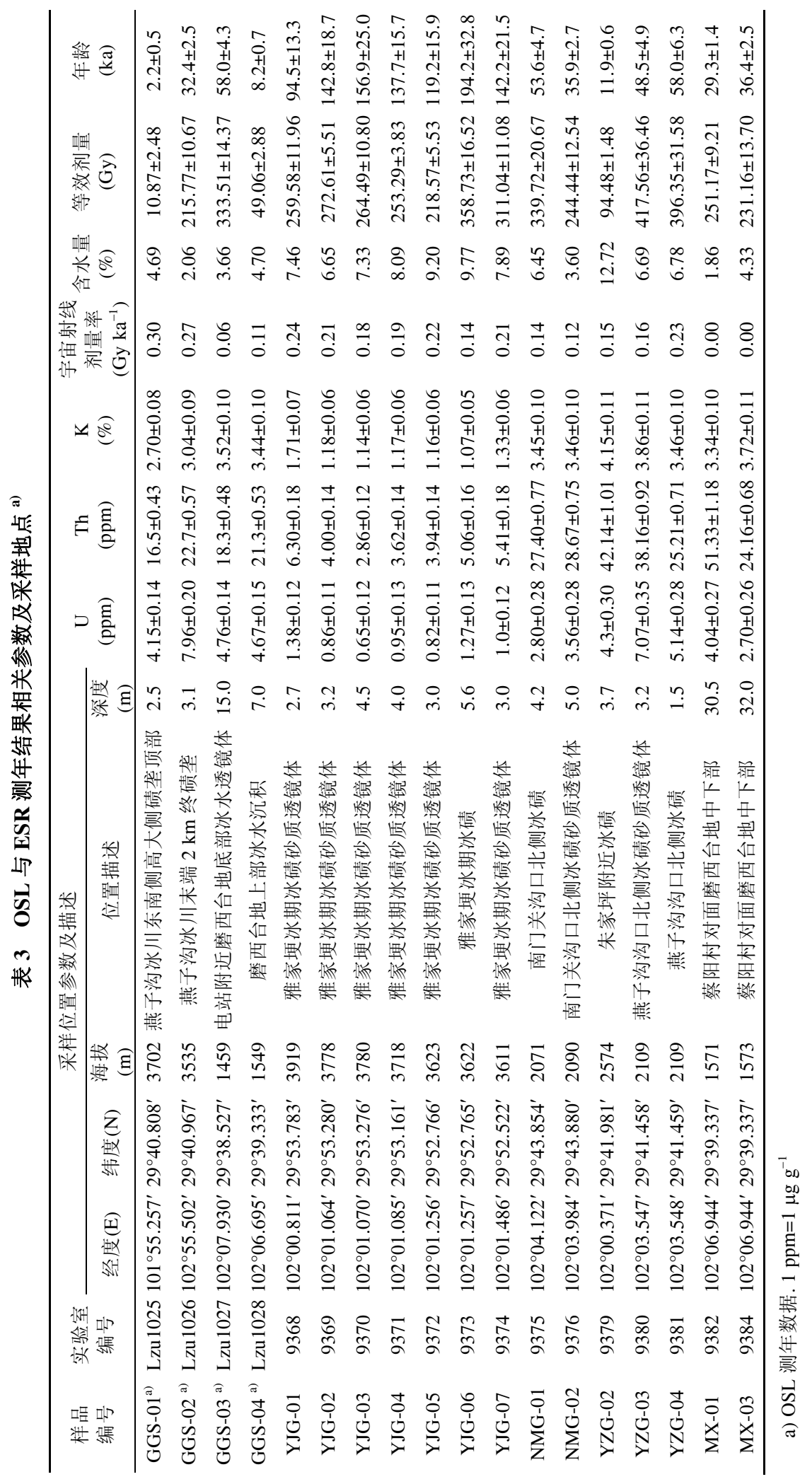




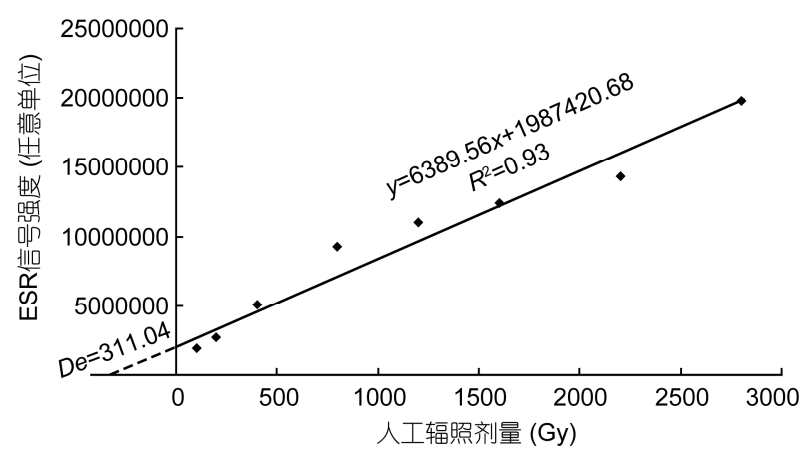

图 6 YJG-07 样品人工辐照剂量与 ESR 信号强度之间的线 性拟合曲线

本次测试的样品均采自海拔较高的地区, 太阳光中 紫外光的强度远比低海拔的地方大. 因此, 冰川沉积 中石英颗粒的 Ge 心理论上满足 ESR 测年中信号回零 的这一先决条件, 以往的研究也表明 ESR 技术对冰 川沉积直接定年是可行和可靠的 ${ }^{[4,5,7,38,39,48]}$. 该次所 测 ESR 年代中, 仅 YJG-01 年龄出现较大偏差, 可能 由于其太靠近雅家埂东坡的支沟，不排除受后期冰 川作用重新改造的影响. 其余结果基本符合地貌地 层学推断的新老关系, 同套冰碛上也均获得了较一 致的测年结果, 且与相应冰水沉积的 OSL 年龄具有 很好对应关系.

\section{4 结果与讨论}

\section{1 冰川沉积序列}

海螺沟谷地第一套冰碛最外一列终碛垄外侧 $(3730 \mathrm{~m})$ 朽木 ${ }^{14} \mathrm{C}$ 测年为 $(0.58 \pm 0.08) \mathrm{cal} \mathrm{ka} \mathrm{BP}$, 最里 一列侧碛所采朽木 ${ }^{14} \mathrm{C}$ 测年为 $(0.17 \pm 0.12) \mathrm{cal} \mathrm{ka} \mathrm{BP}{ }^{[21]}$, 以此判定这些新鲜冰碛垄为小冰期的冰碛.

海螺沟中第二套冰碛内侧碛 ${ }^{14} \mathrm{C}$ 测年为 $(0.84 \pm 0.10) \mathrm{cal} \mathrm{ka} \mathrm{BP}{ }^{[18]}$, 中间侧碛 ${ }^{14} \mathrm{C}$ 测年为 $(1.44 \pm 0.13) \sim(1.46 \pm 0.11) \mathrm{cal} \mathrm{ka} \mathrm{BP} P^{[18,21]}$, 与西藏若果 冰川 $((1.45 \pm 0.16) \sim(1.87 \pm 0.27)$ cal ka BP $)$ 冰进相当 ${ }^{[29]}$; 外侧碛 ${ }^{14} \mathrm{C}$ 测年 $(2.53 \pm 0.19) \sim(3.26 \pm 0.20) \mathrm{cal} \mathrm{ka} \mathrm{BP}$, 可 与藏东南雪当冰进相当 ${ }^{[21]}$, 当时海螺沟冰川比现代 冰川长约 $3 \mathrm{~km}$. 海螺沟第一和第二套冰碛的 TCN ${ }^{10} \mathrm{Be}$ 暴露测年与上述结果基本相符 ${ }^{[11]}$. 小南关沟海 拔 $3200 \mathrm{~m}$ 处冰碛物中朽木 ${ }^{14} \mathrm{C}$ 测年为 $(0.77 \pm 0.14) \mathrm{cal}$ $\mathrm{ka} \mathrm{BP}^{[21]}$. 燕子沟冰川两侧高大的侧碛的 OSL 年代为 $(2.2 \pm 0.5) \mathrm{ka}$. 这些数据表明第二套冰碛形成于新冰
期.

第三套冰碛热水沟口一带冰碛剖面中层淤泥的 ${ }^{14} \mathrm{C}$ 测年为 $(29.25 \pm 1.51) \mathrm{cal} \mathrm{ka} \mathrm{BP} P^{[19]}$, 上层冰碛泉华 盖层的 ${ }^{14} \mathrm{C}$ 测年为 $(21.31 \pm 0.85) \mathrm{cal} \mathrm{ka} \mathrm{BP}^{[18]}$. 燕子沟 朱家坪附近冰碛物的 $\mathrm{ESR}$ 年代为 $(11.9 \pm 0.6) \mathrm{ka}$. 海螺 沟中该套冰碛的 $\mathrm{TCN}{ }^{10} \mathrm{Be}$ 暴露年龄为 $(7.94 \pm 0.68) ~$ $(9.15 \pm 0.50) \mathrm{ka}^{[11]}$, 比上述年代要年轻, 但应注意到它 们代表的是冰川开始退缩的时代, 更重要的是未经 表面侵蚀的校正. 研究表明, 与贡嘎山地区同样具有 丰富降水的青藏高原东南部地区，末次间冰期以来 出露地表岩石的平均剥蚀速率可达到 $(27.1 \pm 10.2) \mathrm{mm}$ $\mathrm{ka}^{-1[49]}$. 导致漂砾表面的剥蚀非常严重, 这就可能会 使获得的 ${ }^{10} \mathrm{Be}$ 暴露测年结果比实际年龄要年轻的多. 因此，笔者综合已有的年代资料认为第三套冰碛(贡 嘎冰期)形成于末次冰盛期 (global Last Glacial Maximum, $\mathrm{LGM}_{\mathrm{G}}$ ), 对应于 MIS2.

早期根据地貌地层学原理和相邻已知的地层年 代对比判读, 第四套冰碛(南门关冰碛)的时代可能为 中更新时晚期的倒数第二次冰期(MIS6) ${ }^{[22,23]}$. 南门 关沟口北侧跃进坪冰碛平台上两个样品的 ESR 年代 为 $(35.9 \pm 2.7)$ 和 $(53.6 \pm 4.7) \mathrm{ka}$, 燕子沟沟口北侧冰碛平 台上两个样品的 $\mathrm{ESR}$ 年代为 $(48.5 \pm 4.9)$ 和 $(58.0 \pm 6.3)$ ka. 说明第四套冰碛(南门关冰期)应形成于末次冰期 中冰阶, 与 MIS3 中期相对应, 也显示出本区末次冰 期冰川规模最大(local last glacial maximum, $\mathrm{LGM}_{\mathrm{L}}$ ) 出 现在末次冰期中冰阶, 而不是 $\mathrm{LGM}_{\mathrm{G}}$. 随着第四纪冰 川年代数据的增加, 越来越多的资料显示全球各地 冰期启动时间和冰川进退历史并非完全一致. Gillespie 和 Molnar ${ }^{[50]}$ 较早论述山地冰川与大陆冰盖 的异时性时, 首先提出喜马拉雅山西段 $\mathrm{LGM}_{\mathrm{L}}$ 对应于 MIS3．随后 Phillips 等 ${ }^{[11]}$ 和 Owen 等 ${ }^{[6]}$ 在青藏高原南 缘受西南季风影响的地区证实了这种现象. 近期的 资料显示沙鲁里山 ${ }^{[4]}$ 、雀儿山 ${ }^{[52]}$ 、阿尼玛卿和年保玉 则山 ${ }^{[10]}$ 以及台湾山地 ${ }^{[53]}$ 等其他受季风环流控制的区 域也存在同样的事实. 古里雅冰芯的记录显示 MIS3(58 32ka) 时出现了两暖峰夹一冷谷剧烈的气候 波动 ${ }^{[54]}$ (图 7(c)), 其中早、晚亚阶段温度已经高出现 代 3 和 $4^{\circ} \mathrm{C}$, 达到间冰期程度, 而中亚阶段又相当寒 冷, 低于现代 $5^{\circ} \mathrm{C}^{[55]}$. 利用湖泊水体氧同位素的特征 建立起来的若尔盖盆地 $\mathrm{RM}$ 钻孔古温度曲线也清楚 的显示, MIS3 是双峰一谷的特征, 内部温差在 $4^{\circ} \mathrm{C}$ 以

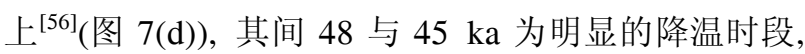

1896 




图 7 贡嘎山东坡第四纪冰川测年数据与不同气候记录的对比

(a) 测年结果及误差; (b) 深海氧同位素阶段; (c) 古里雅冰芯 ${ }^{[54]}$; (d) 若尔盖盆地 RM 钻孔 ${ }^{[56]}$; (e) LR04 深海氧同位素曲线 ${ }^{[61]}$; (f) CLIMBER II 模拟的 6,7 和 8 月南亚季风降水 ${ }^{[62]}$

其中 $48 \mathrm{ka}$ 左右的降温事件可与 Heinrich 5 相对照 ${ }^{[57]}$. 另外, MIS3 时太阳辐射较高, 可激发南亚夏季风增 强, 可以给上述这些地区带来较多的降水(高海拔地 区以固态降水为主) ${ }^{[6,50,55]}$ (图 7(f)); 地貌和沉积记录 也表明, MIS3 中后期在青藏高原及周边的许多大湖 由于丰富的降水出现了高湖面 ${ }^{[58,59]}$. 因此, 笔者认为 MIS3 时南亚季风携带印度洋和孟加拉湾的水汽沿青 藏高原东南部的深切河谷北上, 在西藏东南部和横 断山地区形成较为丰富的降水, 结合 MIS3 中期的低 温, 使得贡嘎山地区冰川呈现正物质平衡, 并有较大 规模前进. 此外, 西藏东南部的孢粉记录显示, $\mathrm{LGM}_{\mathrm{G}}$ 时的年降水量仅为 $250 \mathrm{~mm}$ 左右, 是目前该地 的 $40 \%{ }^{[60]}$, 干冷的气候反而抑制了冰川的发育(图 7(c) 和(e)), 这也是 MIS3 中期冰川规模比 $\mathrm{LGM}_{\mathrm{G}}$ 时大的原 因之所在.

雅家附近的样品, 除 YJG-01 偏离平均年龄较大 外, 其他 6 个样品(YJG-02 07)的 ESR 测年结果较一 致, 位于(119.2 \pm 15.9$) \sim(194.2 \pm 32.8) \mathrm{ka}$ (表 2). 说明其 第五套冰碛(雅家梗冰期)形成于倒数第二次冰期, 可 与 MIS6 相对应, 而不是早期认为的中更新世早期的 倒数第三次冰期. 全球标准深海氧同位素曲线显示,
MIS6 是温度异常低持续时间非常长的时段 ${ }^{[61]}$ (图 7(e)); 若尔盖盆地 RM 钻孔的记录表明, 140 160 ka 时的温度比目前低 $4.3^{\circ} \mathrm{C}^{[57]}$ (图 7(d)).

贡嘎山作为青藏高原东缘的极高山地, 可能出 现过早于 MIS6 的冰川作用. 但该区域的地形坡度较 大, 多在 $30^{\circ}$ 以上; 冰川是典型的季风海洋型, 积累 量大, 消融强, 运动速度快, 侵蚀搬用能力强, 冰川 沉积物丰富; 降水丰富, 加之海洋型冰川对温度的反 应比较灵敏, 遇气候转暖时冰川融水大量增加, 冰川 洪水和泥石流频繁发生. 因此, 块体运动和流水作用 引起侵蚀切割作用强烈, 也经常致使冰川和其他地 形的重新堆积, 而不像高原其他较干旱的地区那样 能够保留很老的冰川作用遗迹. 不过本区是否保存 有更老的冰碛值得继续深入探讨.

\section{2 磨西台地的成因及形成时代}

磨西台地所处的磨西河谷地是区域性康定-磨西 断层通过的地段, 有近东西向的海螺沟、磨子沟、燕 子沟断层与之交汇，是由冰川、流水和泥石流等侵蚀 下发育而成 ${ }^{[16,63]}$. 磨西饭店以下的磨西台地部分所 露剖面均为略具层理的冰水沉积. 新兴乡一带的磨 
西面上散布有许多花岗岩和变质岩的大漂砾(10 $20 \mathrm{~m}$ ), 有的漂砾表面能见到磨光面和冰川刻槽. 期 间修路、建房挖地基、修排水沟时多有冰碛、冰水沉 积被挖掘出来; 而相应的河流阶地砾石层中的巨石 少而小. 因此, 有关磨西台地的成因有多种解释, 其 形成年代也尚存有争议. Heim ${ }^{[12]}$ 考察后认为磨西面 系燕子沟流出来的末次冰期的冰水沉积物. 李承三 ${ }^{[64]}$ 提出 3 种可能的成因: 冰川生成的底碛; 气候转 暖、雪线上升时的洪积; 山地上升、侵蚀加强生成的 冲积层. 崔之久 ${ }^{[14]}$ 认为磨西台地底部有非冰水物质 存在, 可能为较老的冰碛. 1979 1980 年中国科学院 成都地理研究所根据磨西台地及两侧级阶地的研究, 推断磨西面为全新世早期夹有泥石流堆积层的冲积 阶地 ${ }^{[16]}$. 郑本兴 ${ }^{[22]}$ 认为磨西台地的主体是磨西台地 的主体是南门关冰期的冰川堆积(也包括冰水砂砾层 透镜体和冰湖相等沉积), 磨西面上的巨砾应为冰上 融出碛的裸露大漂砾, 其中也包含冰川泥石流夹带 的巨石(冰川沉积再搬运).

南门关冰期时燕子沟冰川进入磨西河谷后汇合 磨子沟冰川, 一直伸到磨西镇下街磨西饭店北, 古冰 川阻塞主谷, 在新兴与南门关沟之间形成冰川阻塞 湖; 在磨西镇上街东侧, 该期古冰川覆盖在谢家河坝 东面山坡上, 融水深切形成峡谷, 而磨西下街为古冰 川消融碛(可能包含部分冰川泥石流沉积 $)^{[22]}$. 新兴乡 至磨西镇大杉树一带以及磨西上街与中街之间的地 形与一般河谷阶地面向下游倾渐变斜不同, 而是呈 台阶状降低, 类似于冰川多次后退停顿所形成的冰 碛台地系列.

新兴乡以东 $\mathrm{T}_{4}$ 阶地底部褐色淤泥层中朽木的 ${ }^{14} \mathrm{C}$ 年代为 $(8.22 \pm 0.29) \sim(8.25 \pm 0.57) \mathrm{cal} \mathrm{ka} \mathrm{BP}{ }^{[17]}$; 磨西 河柏家山附近 $\mathrm{T}_{2}$ 阶地底部的 ${ }^{14} \mathrm{C}$ 年龄为 $(2.46 \pm 0.17) \mathrm{cal}$ $\mathrm{ka} \mathrm{BP}{ }^{[17]}$; 燕子沟药王庙上游 $1 \mathrm{~km}$ 处 $\mathrm{T}_{2}$ 中上部的 ${ }^{14} \mathrm{C}$
测年为 $(1.41 \pm 0.12) \mathrm{cal} \mathrm{ka} \mathrm{BP} \mathrm{P}^{[17]}$, 而上游小南关沟口 附近 $\mathrm{T}_{1}$ 阶地的 ${ }^{14} \mathrm{C}$ 年代为 $(0.69 \pm 0.04) \mathrm{cal} \mathrm{ka} \mathrm{BP}{ }^{[16]}$; 海 螺沟观景台附近 $\mathrm{T}_{1}$ 砾石层中朽木 ${ }^{14} \mathrm{C}$ 年代为 $(0.85 \pm 0.07) \mathrm{cal} \mathrm{ka} \mathrm{BP}, \mathrm{T}_{2}$ 阶地砾石层所夹淤泥层的 ${ }^{14} \mathrm{C}$ 年代为 $(1.13 \pm 0.15) \sim(2.18 \pm 0.15) \mathrm{cal} \mathrm{ka} \mathrm{BP} \mathrm{P}^{[21]}$. 这些 年代数据表明该地区阶地的形成无疑与末次冰期后 冰川融水有密切联系. 另外, 蔡阳坪对面磨西台地上 部 OSL 年代为 $(8.2 \pm 0.7) \mathrm{ka}(\mathrm{GGS}-04)$. 磨西台地顶部 的 6 个样品 $\mathrm{TCN}{ }^{10} \mathrm{Be}$ 的暴露年龄为 $(3.27 \pm 0.43) \sim$ $(6.27 \pm 0.47) \mathrm{ka}^{[11]}$. 中下部两个样品的 $\mathrm{ESR}$ 年代为 (29.3 \pm 1.4$) \mathrm{ka}(\mathrm{MX}-01)$ 和(36.4 \pm 2.5$) \mathrm{ka}(\mathrm{MX}-03)$, 磨西 台地尾端电站附近磨西台地底部 OSL 年代为 (58.0 \pm 4.3$) \mathrm{ka}$, 都对应于 MIS3. 磨西台地和两侧阶地 地貌特征、沉积剖面结构特征与组成的分析以及上述 测年结果, 表明磨西饭店以上的磨西台地中上部、两 侧阶地及磨西饭店以下的部分均为 MIS3 至全新世的 混杂有泥石流堆积的冰水沉积; 而底部主要是南门 关冰期(MIS3 中期)的冰川沉积, 其中包含有冰水砂 砾石层透镜体和冰湖相等沉积.

\section{5 结论}

贡嘎山的东坡至少经历了 5 次规模较大的冰进, 分别对应于小冰期、新冰期、MIS2, MIS3 中期和 MIS6. 该区域的末次冰期冰川规模最大不是发生在末次冰 期最盛期 $\left(\mathrm{LGM}_{\mathrm{G}}\right)$, 而是较为冷湿的 MIS3 中期. 早期 划定的贡嘎、南门关和雅家埂冰期分别对应于末次冰 期晚冰阶、中冰阶和倒数第二次冰期(MIS6). 磨西台 地中上部、两侧阶地及尾部均为 MIS3 至全新世的混 杂有泥石流堆积的冰水沉积; 而底部主要是南门关 冰期(MIS3 中期)的冰川沉积, 其中包含有冰水砂砾 石层透镜体和冰湖相等沉积.

致谢中国地震局地质所新构造年代学实验室李建平、中国原子能科学研究院的倪邦发与兰州大学西部环境教育部 重点实验室的范育新在年代测定中给予帮助, 审稿专家提出宝贵意见, 在此一并感谢.

\section{参考文献}

1 崔之久, 张威. 末次冰期冰川规模与冰川异时、同时问题的讨论. 冰川冻土, 2003, 25: 510-516

2 Zhou S Z, Xu L B, Wang J, et al. A preliminary study on timing of the oldest Pleistocene glaciation in Qinghai-Tibetan Plateau. Quat Int, 2006, 154/155: 44-51

3 周尚哲, 许刘兵, Colgan P M, 等. 古乡冰期和白玉冰期的宇宙成因核素 ${ }^{10} \mathrm{Be}$ 定年. 科学通报, 2007, 52: 945-950

4 Xu L B, Zhou S Z. Quaternary glaciations recorded by glacial and fluvial landforms in the Shaluli Mountains, Southeastern Tibetan Plateau.

1898 
Geomorphology, 2009, 103: 268-275

5 Yi C L, Li X Z, Qu J J. Quaternary glaciation of Puruogangri-The largest modern ice field in Tibet. Quat Int, 2002, 97-98: 111-121

6 Owen L A, Finkel R C, Caffee M W. A note on the extent of glaciation throughout the Himalaya during the global Last Glacial Maximum. Quat Sci Rev, 2002, 21: 147-157

7 王杰, 周尚哲, 赵井东, 等. 东帕米尔公格尔山地区第四纪冰川地貌与冰期. 中国科学: 地球科学, 2011, 41: 350-361

8 张威, 牛云博, 间玲, 等. 吉林长白山地晚更新世冰川作用. 科学通报, 2008, 53: 1825-1834

9 Seong Y B, Owen L A, Yi C L, et al. Quaternary glaciation of Muztag Ata and Kongur Shan: Evidence for glacier response to rapid climate changes throughout the Late Glacial and Holocene in westernmost Tibet. Geol Soc Am Bull, 2009, 121: 348-365

10 Owen L A, Finkel R C, Ma H Z, et al. Timing and style of late Quaternary glaciation in northeastern Tibet. Geol Soc Am Bull, 2003, 115: 1356-1364

11 Owen L A, Finkel R C, Barnard P L, et al. Climatic and topographic controls on the style and timing of Late Quaternary glaciation throughout Tibet and the Himalaya defined by ${ }^{10} \mathrm{Be}$ cosmogenic radionuclide surface exposure dating. Quat Sci Rev, 2005, 24: 1391-1411

12 Heim A. The glaciation and solifluction on Minya Gongkar. Geogr J, 1936, 87: 444-454

13 Anderson J G. Topographical and Archaeological Studies in the Far East. Bull Museum Far Eastern Autiq, 1939, 11: 7-22

14 崔之久. 贡嘎山现代冰川的初步观察. 地理学报, 1958, 24: 318-338

15 范文纪. 贡嘎山的地质构造基础和冰川地貌特征. 成都科技大学学报, 1982, (3): 19-28

16 刘淑珍, 刘新民, 赵永涛, 等. 贡嘎地区地貌特征及地貌发育史. 见: 中国科学院成都地理研究所, 编. 贡嘎山地理考察. 重庆: 科 学技术文献出版社重庆分社, 1983.21-34

17 李钟武, 陈继良, 胡发德, 等. 贡嘎山地区地质构造. 见: 中国科学院成都地理研究所, 编. 贡嘎山地理考察. 重庆: 科学技术文献 出版社重庆分社, 1983.4-20

18 李吉均, 宋明琨, 秦大河, 等. 贡嘎山冰川考察. 见: 中国科学院青藏高原综合科学考察队, 编. 横断山考察专辑(一). 昆明: 云南人 民出版社, 1983. 140-153

19 王明龙, 胡发德, 李钟武. 贡嚘山地区第四纪冰期探讨. 见: 高生淮, 郑远昌, 编. 横断山研究文集. 成都: 四川科学技术出版社, 1989. 50-58

20 Su Z, Liu S Y, Wang L L, et al. Recent fluctuations of glaciers in the Gongga Mountains. Ann Glaciol, 1992, 16: 163-167

21 郑本兴, 马秋华. 贡嘎山区全新世冰川变化、气候变化与河流阶地发育. 地理学报, 1994, 46: 500-508

22 郑本兴. 贡嘎山东麓第四纪冰川作用与磨西台地成因探讨. 冰川冻土, 2001, 23: 283-291

23 苏珍, 施雅风, 郑本兴. 贡嘎山第四纪冰川遗迹及冰期划分. 地球科学进展, 2002, 17: 639-647

24 刘淑珍. 贡嘎山地区地貌类型及制图. 见: 中国科学院青藏高原综合科学考察队, 编. 横断山考察专辑(一). 昆明: 云南人民出版社, 1983. $114-123$

25 蒲健辰. 中国冰川目录VIII一长江水系. 兰州: 甘肃文化出版社, 1994. 117-129

26 苏珍, 梁大兰, 洪明. 贡嘎山海洋性冰川发育条件及分布特征. 冰川冻土, 15: 551-557

27 Zheng B X, Rutter N. On the problem of Quaternary glaciations, and the extent and patterns of Pleistonce ice cover in the Qinghai-Xizang (Tibet) Plateau. Quat Int, 1998, 45/46: 109-122

28 Reimer P J, Baillie M G L, Bard E, et al. Intcal04 terrestrial radiocarbon age calibration, 0-26 cal kyr BP. Radiocarbon, 2004, 46: $1029-1058$

29 李吉均, 郑本兴, 杨锡金, 等. 西藏冰川. 北京: 科学出版社, 1986. 138-140

30 李国强, 赵晖, 范育新, 等. 光释光测年中石英样品提纯方法的改进. 地球科学进展, 2008, 23: 284-289

31 Murray A S, Wintle A G. Luminescence dating of quartz using an improved single-aliquot regenerative-dose protocol. Radiat Meas, 2000, 32: $57-73$

32 Prescott J R, Hutton J T. Cosmic ray contributions to dose rates for luminescence and ESR dating: Large depths and long-term time variations. Radiat Meas, 1994, 23: 497-500

33 Fuchs M, Owen L A. Luminescence dating of glacial and associated sediments: Review, recommendations and future directions. Boreas, 2008, 37: 636-659

34 Thrasher I M, Mauz B, Chiverrell R C, et al. Luminescence dating of glaciofluvial deposits: A review. Earth-Sci Rev, 2009, 97: 133-146

35 Duller G A T. Single grain optical dating of glacigenic deposits. Quat Geochronol, 2006, 1: 296-304

36 Ou X J, Xu L B, Lai Z P, et al. Potential of quartz OSL dating on moraine deposits from eastern Tibetan Plateau using SAR protocol. Quat Geochronol, 2010, 5: 257-262

37 Walther R, Zilles D. ESR studies on bleached sedimentary quartz. Quat Geochronol (Quat Sci Rev), 1994, 13: 611-614 
38 Rink W J. Electron Spin Resonance (ESR) dating and ESR applications in Quaternary science and archaeometry. Radiat Meas, 1997, 27: 975-1025

39 Zhao J D, Song Y G, King J W, et al. Glacial geomorphology and glacial history of the Muzart River valley, Tianshan range, China. Quat Sci Rev, 2010, 29: 1453-1463

40 Zhao J D, Liu S Y, He Y Q, et al. Quaternary glacial chronology of the Ateaoyinake River Valley, Tianshan Mountains, China. Geomorphology, 2009, 103: 276-284

41 Tanaka T, Sawada S, Ito T. ESR dating of late Pleistocene near-shore and terrace sands. In: Ikeya M, Miki T, eds. ESR Dating and Dosimetry. Tokyo: Ionics, 1986. 275-280

42 Buhay W M, Schwarcz H P, Grün R. ESR dating of fault gouge: The effect of grain size. Quat Sci Rev, 1988, 7: 515-522

43 Ye Y G, Diao S B, He J, et al. ESR dating studies of paleo-debris-flows deposition Dongchuan, Yunnan Province, China. Quat Sci Rev, 1998, 17: 1073-1076

44 李吉均. 山地冰川地貌的形成机制及其识别. 见: 施雅风, 崔之久, 李吉均, 等, 编. 中国东部第四纪冰川与环境问题. 北京: 科学 出版社, 1989. 13-26

45 Mahaney W C, Vortisch W, Julig P J. Relative differences between glacially crushed quartz transported by mountain and continental ice: Some examples from North America and East Africa. Am J Sci, 1988, 288: 810-826

46 Yi C L. Subglacial comminution: Evidence from microfabric studies and grain size analysis. J Glaciol, 1997, 43: 174-179

47 金嗣炤, 邓中, 黄培华. 黄土石英 $\mathrm{E}^{\prime}$ 中心光效应研究. 科学通报, 1991, 36: 741-744

48 Zhao J D, Zhou S Z, He Y Q, et al. ESR dating of glacial tills and glaciations in the Urumqi River headwaters, Tianshan Mountains, China. Quat Int, 2006, 144: 61-67

49 许刘兵, 周尚哲. 基于宇宙成因核素 ${ }^{10} \mathrm{Be}$ 的青藏高原东南部地区未次间冰期以来地表岩石剥蚀速率研究. 地质学报, 2009, 83: 487-495

50 Gillespie A, Molnar P. Asynchronous maximum advances of mountain and continental glaciers. Rev Geophys, 1995, 33: 311-364

51 Phillips W M, Sloan V F, Shroder J F, et al. Asynchronous glaciation at Nanga Parbat northwestern Himalaya Mountains, Pakistau. Geology, 2000, 28: 431-434

52 Xu L B, Ou X J, Lai Z P, et al. Timing and style of Late Pleistocene glaciation in the Queer Shan, northern Hengduan Mountains in the eastern Tibetan Plateau. J Quat Sci, 2010, 25: 957-966

53 Cui Z J, Yang C F, Liu G N, et al. The Quaternary glaciation of Shesan Mountain in Taiwan and glacial classification in monsoon areas. Quat Int, 2002, 97/98: 147-153

54 姚檀栋, Thompson L G, 施雅风, 等. 古里雅冰芯中末次间冰期以来气候变化记录研究. 中国科学 D 辑: 地球科学, 1997, 27: 447-452

55 施雅风, 姚檀栋. 中低纬度 MIS3b(54 44 ka BP)冷期与冰川前进. 冰川冻土, 2002, 24: 1-9

56 吴敬禄, 王苏民, 施雅风, 等. 若尔盖盆地 $200 \mathrm{ka}$ 以来氧同位素记录的古温度定量研究. 中国科学 D 辑: 地球科学, 2000, 30: 73-80

57 吴敬禄, 王苏民, 潘红胥, 等. 青藏高原东部 RM 孔 $140 \mathrm{ka}$ 以来湖泊碳酸盐同位素记录的古气候特征. 中国科学 D 辑: 地球科学, 1997, 27: 255-259

58 Zhang H C, Wünnemann B, Ma Y Z, et al. Lake level and climate changes between 42000 and $18000{ }^{14} \mathrm{C}$ yr BP in the Tengger Desert, Northwestern China. Quat Res, 2002, 58: 62-72

59 Herzschuh U. Palaeo-moisture evolution in monsoonal Central Asia during the last 50000 years. Quat Sci Rev, 2006, 25: 163-178

60 唐领余, 沈才明, 廖洤标, 等. 末次盛冰期以来西藏东南部的气候变化. 中国科学 D 辑: 地球科学, 2004, 34: 436-442

61 Lisiecki L E, Raymo M E. A Pliocene-Pleistocene stack of 57 globally distributed benthic $\delta^{18} \mathrm{O}$ records. Paleoceanography, 2005, 20: PA1003

62 Ziegler, M. Orbital forcing of the late Pleistocene boreal summer monsoon: Links to North Atlantic cold events and the El Niño-Southern Oscillation. Doctor Dissertation. Utrecht: Utrecht University, 2009. 38-39

63 吕儒仁, 赵惠林. 贡嘎山东坡全新世泥石流活动与环境演变. 见: 陈富斌, 罗辑, 编. 贡嘎山高山生态环境研究(第 2 卷). 北京: 气象 出版社, 1998. 90-101

64 李承三. 西康泸定磨西面之水利问题. 地质论评, 1939, 4: 367-372 